\title{
ANALISIS SWOT DAYA SAING SEKOLAH: STUDI KASUS DI SEKOLAH MENENGAH KEJURUAN NEGERI 1 PASIR PENYU INDRAGIRI HULU, RIAU
}

\author{
Rini Setyaningsih ${ }^{\left.a^{*}\right)}$, Herlin Wulandari ${ }^{a)}$ \\ a) UIN Sultan Syarif Kasim, Riau, Indonesia \\ ${ }^{*}$ e-mail korespondensi: rinisetyaningsih2010@gmail.com
}

riwayat artikel : diterima: 18 November 2019; direvisi: 26 Desember 2019; disetujui: 18 Januari 2020

\begin{abstract}
Abstrak. Salah satu karakteristik untuk melihat daya saing sebuah sekolah adalah peringkat akreditasinya. Sekolah yang sudah terakreditasi A dapat dikatakan berpeluang besar dalam menyusun strategi efektif untuk meningkatkan daya saing. Tujuan penelitian ini adalah untuk mengetahui posisi strategi dari SMK N 1 Pasir Penyu dengan analisis SWOT yakni Strenghts, Weaknesses, Opportunities, dan Threats. Keseluruhan data didapati oleh peneliti melalui wawancara, studi literatur, observasi, dan dokumen, serta kuesioner. Analisis data yang peneliti lakukan yakni dengan IFAS dan EFAS, lalu kemudian analisis SWOT untuk mengetahui beberapa faktor internal dan eksternal serta untuk mengidentifikasi sebuah posisi strategi SMK N 1 Pasir Penyu. Hasil penelitian ini menunjukkan bahwa SMK N 1 Pasir Penyu terletak pada posisi kuadran I (Agresif), yakni berarti bahwa SMK N 1 Pasir Penyu berada dalam taraf survival. Saran peneliti untuk SMK N 1 Pasir Penyu, agar mampu membenahi beberapa faktor kelemahan internal yang ada. Untuk dapat menghindari dan mengurangi ancaman dari persaingan antar sekolah, SMK N 1 Pasir Penyu dapat membuat kompetisi unik sebagai pembeda di antara sekolah sejenis.
\end{abstract}

Kata Kunci: IFAS, analisis SWOT, Agresif, EFAS

\section{SCHOOL COMPETITIVENESS SWOT ANALYSIS: A CASE STUDY IN SMKN 1 PASIR PENYU INDRAGIRI HULU, RIAU}

\begin{abstract}
One of the characteristics to see the competitiveness of a school is its accreditation ranking. Schools that have been accredited A can be said to have a great opportunity in developing effective strategies to improve competitiveness. The purpose of this study was to determine the strategic position of SMK N 1 Pasir Penyu with SWOT analysis (Strengths, Weaknesses, Opportunities, and Threats). All data were found by researchers through interviews, literature studies, observations, and documents, and questionnaires. Analysis of the data the researcher did was IFAS and EFAS, then SWOT analysis to find out some internal and external factors and to identify a strategic position of SMK N 1 Pasir Penyu. The results of this study indicate that SMK N 1 Pasir Penyu is located in quadrant I position (Aggressive), which means that SMK N 1 Pasir Penyu is in the survival stage. Researcher's suggestion for SMK N 1 Pasir Penyu is to be able to fix several internal weaknesses. To be able to avoid and reduce the threat of competition between schools, SMK 1 Pasir Penyu can create a unique competition as a differentiator between similar schools
\end{abstract}

Keywords: IFAS; SWOT analysis; Aggressive; EFAS.

\section{PENDAHULUAN}

Salah satu cirri dari sekolah yang mempunyai mutu adalah sekolah yang merespon kepercayaan dari masyarakat serta pemerintah. Dimana dengan artian sekolah dapat memberikan pelayanan yang baik dan prima untuk para muridnya, sehingga menghasilkan alumni-alumni yang bermutu pada bidangnya. Mencetak alumni yang dapat mengikuti perkembangan zaman saat ini sudah menjadi tuntutan para stakeholders yakni pihak sekolah, pemerintah, serta masyarakat dalam melakukan pembenahan. Salah satunya dalam hal sumber daya manusia yang berkualitas dan profesional, manejemen yang handal, kegiatan belajar mengajar yang berkualitas, serta akses terhadap lembaga pendidikan yang lebih tinggi.

Untuk dapat meningkatkan kualitas sumber daya manusia (SDM) unggul yang mampu berdayasaing diperlukan sarana industri yang bergerak di bidang jasa pendidikan, dan sekolah adalah salah satunya. Jika sekolah tidak mampu merespon sebuah peluang atau ancaman baik eksternal maupun internal, maka akan berakibat terhambatnya pencapaian kinerja dan menurunnya daya saing antar sekolah lainnya (Rahayu, 2008). Apabila hal demikian dibiarkan, maka dampaknya dapat mengancam kelangsungan sekolah yang bersangkutan.

Penyedia jasa pendidikan dinamakan lembaga pendidikan atau sekolah berusaha untuk meningkatkan kepuasan serta memenuhi kebutuhan seluruh pelanggannya yaitu seluruh murid yang dimilikinya dengan meningkatkan mutu sekolah. Menurut Sagala (2010) bahwa mutu pendidikan dapat diartikan sebagai gambaran dan karakteristik yang menyeluruh pada jasa pelayanan pendidikan secara internal atau eksternal yang tertuju kepada kemampuan untuk memuaskan kebutuhan pelanggan yang diharapkan. Senada dengan pendapat Marginson dan Wende yakni adanya hubungan antara istilah daya saing dalam bidang pendidikan dengan kata keunggulan, reputasi, dan status (Marginson \& Wende: 2007) 
Salah satu dalam strategi manajerial yang dikembangkan untuk meningkatkan daya saing sekolahserta memiliki daya tahan dan daya hidup yang lama serta kemajuan yang terus menerus berkelanjutan yaitu dengan melakukan analisis SWOT.Analisis SWOT merupakan identifikasi berbagai faktor-faktor sistematis untuk merumuskan strategi sebuah organisasi baik perusahan bisnis maupun instansi lembaga pendidikan. Analisis yang didasarkan dengan logika secara memaksimalkan kekuatan dan peluang kemudian meminimalkan kelemahan dan ancaman. Prosesnya yaitu dengan keputusan strategi yang selalu berkaitan dengan visi, misi, tujuan dan kebijakan-kebijakan program-program dalam instansi tersebut.

\section{Analisis SWOT}

Strengths, Weakness, Opportunities, dan Threats atau biasa disingkat dengan analisis SWOT, merupakan alat yang digunakan untuk mengetahui beberapa isu internal maupun isu eksternal yang dapat mempengaruhi kemampuan pada sebuah lembaga atau organisasi. Analisis SWOT juga merupakan bentuk analisis situasi serta kondisi yang mempunyai sifat deskriptif yang bertujuan untuk memberikan suatu gambaran pada sebuah organisasi.

Analisis ini terbagi menjadi 4 komponen dasar, yaitu :

1. S sama dengan Strengths, situasi atau kondisi yang merupakan kekuatan dari organisasi atau program pada saat ini.

2. W sama dengan Weakness, situasi atau kondisi yang merupakan kelemahaan dari organisasi atau program pada saat ini.

3. O sama dengan Opportunities, situasi atau kondisi yang merupakan sebuah peluang dari organisasi atau program saat ini.

4. T sama dengan Threats, situasi atau kondisi yang merupakan sebuah ancaman dari organisasi atau program pada saat ini.

Analisis SWOT digunakan dalam pendidikan untuk mengevaluasi fungsi pengembangan kurikulum, fungsi perencanaan dan evaluasi, fungsi ketenagaan, fungsi keuangan, fungsi proses belajar mengajar, fungsi pelayanan kesiswaaan, fungsi pengembangan iklim akademik serta fungsi hubungan dengan masyarakat. Untuk mencapai tingkat kesiapan seluruh fungsi tersebut maka dilakukan analisis SWOT. (Depdiknas,2002)

Analisis SWOT adalah identifikasi beberapa faktor secara sistematis untuk merumuskan strategi sebuah perusahaan, yakni setiap perusahaan harus mampu memaksimalkan komponen kekuatan (S/ strength) dan peluang (O/ oppourtunities) dan bisa meminimalkan komponen kelemahan (W/ weakness) serta ancaman (T/ threats) (Rangkuti: 2009). Analisis SWOT mencoba menyeimbangkan antara komponen kekuatan dan kelemahan internal dengan komponen peluang dan komponen ancaman lingkungan eksternal pada sebuah organisasi. Melalui pendekatan ini, isu pertama pada sebuah organisasi harus dianalisis secara teliti dan cermat. Sehingga formulasi strategi harus dapat mengarah kepada berbagai kondisi sebuah organisasi yang penting dan mendesak untuk dapat diatasi.

Analisis SWOT sangat membantu dalam merumuskan beberapa kebijakan yang bersifat strategi bagi bagi sebuah organiasai/ sekolah. Analisis ini berupaya menentukan metoda untuk memanfaatkan secara maksimal seluruh komponen kekuatan yang ada serta komponen peluang yang terbuka, serta meminimalkan semua komponen kelemahan dan ancaman. Sebuah logika bahwa keberhasilan sebuah sekolah atau organisasi ditentukan oleh kondisi internal maupun eksternal merupakan landasan dari analisis SWOT. Analisis ini juga digunakan untuk menganalisis suatu kasus yang kompleks atau dapat menyusun sebuah rencana yang bersifat strategis.

\section{METODE PENELITIAN}

Penelitian ini dilakukan di Sekolah Menengah Kejuruan Negeri 1 Pasir Penyu Kabupaten Indragiri Hulu Provinsi Riau. Jenis penelitian ini adalah kualitatif dan kuantitatif. Metode pengumpulan data melalui wawancara, studi literatur, observasi, dan dokumen, serta kuesioner. Peneliti menggunakan analisis SWOT (Strengths, Weaknesses, Opportunities and Threats) untuk mengalisis keseluruhan data yang peneliti peroleh.

Tempat penelitian ini di SMK N 1 Pasir Penyu, peneliti melakukan beberapa langkah untuk mengetahui dan menggali data, langkah tersbut adalah: Pada tahap pertama menyusun rancangan penelitian, peneliti melakukan persiapan sebelum melakukan penelitian yaitu dengan studi pendahuluan melalui observasi dengan meminta ijin kepada kepala SMK N 1 Pasir Penyu. Observasi dilakukan dengan melihat beberapa kondisi fisik SMK N 1 Pasir Penyu dan mengenali lingkungan sekitar sekolah tersebut. Langkah selanjutnya, peneliti membuat instrumen penelitian berupa panduan wawancara yang berdasarkan studi literatur. Tahap selanjutnya adalah untuk menggali data potensi dan masalah, yakni pada tahap ini peneliti memberikan kuesioner kepada kepala sekolah dan guru untuk mengenali komponen potensi dan mengenali beberapa masalah yang terjadi di sekolah. Kemudian peneliti melakukan diagnosis permasalahan untuk mengetahui beberapa faktor pada komponen kekuatan, kelemahan, peluang dan ancaman melalui hasil kuesioner.

Metode yang digunakan untuk menganalisis data pada penelitian ini adalah menggunakan teknik analisis matrik IFAS (Internal Factor Analysis Summary) dan analisis matrik EFAS (External Factor Analysis Summary) dan analisis matrik SWOT (Strengths Weaknesses Opportunities Threats). Beberapa langkah yang peneliti lakukan dalam analisis SWOT yang peneliti kutip dari (Rangkuti, 2009) adalah sebagai berikut: (1) Mengidentifikasi beberapa faktor yang dapat menjadi komponen kekuatan, kelemahan, peluang dan ancaman yang dihadapai oleh sekolah; (2) Menentukan beberapa faktor yang dapat menjadi komponen kekuatan, kelemahan, peluang dan ancaman yang sekiranya akan dihadapi oleh sekolah dalam meningkatkan mutu; (3) Memberikan bobot masing-masing faktor berdasarkan tingkat kepentingannya mulai dari 1,0 (sangat penting) sampai 
dengan 0,0 (tidak penting). Faktor-faktor tersebut kemungkinan memberi dampak terhadap faktor strategies; (4) Menghitung skor untuk masing - masing faktor dengan memberikan skala mulai dari 4 (outstanding) sampai dengan 1 (poor) berdasarkan pengaruh faktor tersebut terhadap konsisi sekolah yang bersangkutan. Pemberian nilai skor untuk faktor kekuatan atau peluang bersifat positif (kekuatan dan peluang yang semakin besar diberi skor 4, tetapi jika kekuatan atau peluang kecil diberi skor 1). Pemberian skor kelemahan atau ancaman adalah kebalikannya. Jika nilai kelemahan atau ancaman sangat besar maka diberikan skor 1. Maka sebaliknya, jika kelemahan atau ancaman sedikit diberi skor 4; (5) Menghitung total skor dengan mengalikan bobot dan skor untuk masing-masing faktor kekuatan, kelemahan, peluang dan ancaman.

Keseluruhan data SWOT kualitatif yang diperoleh peneliti dapat dikembangkan secara kuantitatif melalui perhitungan analisis SWOT. Sesuai dengan teori yang dikembangkan oleh Pearce dan Robinson (2008) agar diketahui secara pasti posisi usaha atau institusi yang sesungguhnya. Matriks didasarkan pada 2 (dua) dimensi kunci, yakni skor bobot EFAS total pada sumbu X dan skor bobot IFAS total pada sumbu Y, pada matriks ini akan diketahui posisi atau kedudukan strategi sekolah berada pada kuadran yang keberapa dan kedepanya akan dilakukan langkah strategi apa yang harus diperbaiki dan ditempuh dimana dari ke 4 kuadran mempunyai strategi dan evaluasi yang berbeda. Pencocokan yang cermat antara peluang dan ancaman yang dihadapi sekolah dengan kekuatan dan kelemahannya merupakan inti dari formulasi strategi yang tepat.

Kuadran I yaitu pada posisi (positif, positif) artinya menandakan sebuah usaha atau organisasi yang kuat dan berpeluang. Rekomendasi strategi yang diberikan adalah Agresif/ Progresif, artinya organisai tersebut dalam kondisi prima dan mantap sehingga sangat mungkin untuk terus melakukan ekspansi, memperbesar pertumbuhan dan meraih kemajuan secara maksimal.

Kuadran II yaitu pada posisi (positif, negatif) artinya menandakan sebuah organisasi yang kuat namun menghadapi tantangan yang besar. Rekomendasi strategi yang diberikan adalah Strategi Diversifikasi, yang artinya organisasi dalam kondisi mantap namun menghadapi sejumlah tantangan berat sehingga diperkirakan roda organisasi akan mengalami kesulitan untuk terus berputar bila hanya bertumpu pada strategi sebelumnya. Oleh karenanya, organisasi disarankan untuk segera memperbanyak ragam strategi taktisnya.

Kuadran III yaitu pada posisi (negatif, positif) artinya menandakan sebuah organisasi yang lemah namun sangat berpeluang. Rekomendasi strategi yang diberikan adalah Ubah Strategi/ strategi turn around, artinya organisasi disarankan untuk mengubah strategi sebelumnya. Sebab, strategi yang lama dikhawatirkan sulit untuk dapat menangkap peluang yang ada sekaligus memperbaiki kinerja organisasi.

Kuadran IV yaitu pada (negatif, negatif) artinya menandakan sebuah organisasi yang lemah dan menghadapi tantangan besar. Oleh karenanya organisasi disarankan untuk menggunakan strategi bertahan untuk mengendalikan kinerja internal agar tidak semakin terperosok. Strategi ini dipertahankan sambil terus berupaya membenahi diri. Rekomendasi strategi yang diberikan adalah Strategi Bertahan/ strategi defensif, artinya kondisi internal organisasi berada pada pilihan dilematis.

\section{HASIL DAN PEMBAHASAN}

Data yang diperoleh dari hasil kuesioner kemudian dianalisis IFAS dan EFAS, masing-masing faktor dinilai bobot dan ratingnya. Untuk IFAS faktor yang digunakan adalah strength dan weakness sedangkan untuk EFAS faktor yang digunakan adalah Oportunity dan Threat.

Berikut penjelasan faktor internal dan eksternal yang berpengaruh terhadap daya saing SMK N 1 Pasir Penyu:

1. Strength (kekuatan)

a. Mengembangkan kopetensi atau prestasi siswa sesuai dengan kejurusan masing- masing

b. Memiliki fasilitas yang mewadai seperti (ruang belajar, labor,gedung pratektikum, masjid,sarana olahraga,kantin dll)

c. Sekolah tersebut termasuk sekolah Adiwiyata

d. Terletak di kabupaten

e. Output kelulusan $100 \%$

2. Weaknesses (kelemahan)

a. Kurangnya siswa berbisnis dalam kejuruannya masing- masing

b. Banyak informasi lingkungan yang tidak terkontrol

c. Masih ada pemungutan biaya sekolah dari orang tua siswa yang belum efektif dan efesien

d. Kurangnya proses belajar mengajarnya, lebih kejuruannya

e. Masih ada bangunan yang belum efektif

3. Opportunity (peluang)

a. Pemerintahan mempunyai perhatian lebih kepada siswa SMKN 1 Pasir Penyu dalam mengembangkan SDM

b. Memepersiapkan program-program unggul atau bakatnya untuk kedepannya

c. Sekolah mampu bekerja sama dengan intansi lain atau sekolah lain

d. Mempunyai kebijakan atau otoritas dalam mengembangkan sekolah

e. Sekolah bisa untuk lebih maju kedepannya dan dipandang bagus oleh masyarakat

4. Threat (ancaman)

a. Tumbuhnya dan berkembangnya sekolah baru di sekitarnya

b. Masih ada masyarakat yang kurang percaya dan kurang sukasehingga menjelekan sekolah tersebut 
c. Kesulitan sekolah menempatkan siswanya ketika sudah lulus sekolah

d. Lingkungan masyarakat

e. Kurangnya kemajuan teknologi atau bakat dalam menjunjung pembelajaran

Tabel 1: Analisis matriks I-F-A-S (Internal Factor Analysis Strategy)

\begin{tabular}{|c|c|c|c|c|}
\hline Faktor- faktor Strategi Internal & Bobot & Rating & $\begin{array}{l}\text { Bobot* } \\
\text { Rating }\end{array}$ & Komentar \\
\hline $\begin{array}{l}\text { Kekuatan (S) } \\
\text { 1. Mengembangkan kopetensi atau } \\
\text { prestasi siswa sesuai dengan } \\
\text { jurusan masing- masing }\end{array}$ & 0,15 & 3 & 0,45 & $\begin{array}{l}\text { Pemenuhan materi dan praktik untuk meningkatkan } \\
\text { kompetensi atau prestasi dalam pembelajaran peserta } \\
\text { didik }\end{array}$ \\
\hline $\begin{array}{l}\text { 2. Memiliki fasilitas yang mewadai } \\
\text { seperti(ruang belajar, labor,gedung } \\
\text { praktikum, masjid, sarana } \\
\text { olahraga,kantin dll) }\end{array}$ & 0,10 & 4 & 0,40 & $\begin{array}{l}\text { Sekolah ini telah menyiapkan fasilitas yang lengkap agar } \\
\text { siswanya nyaman dalam mengikuti kegiatan pembeljaaran }\end{array}$ \\
\hline $\begin{array}{l}\text { 3. Sekolah tersebut termasuk sekolah } \\
\text { Adiwiyata }\end{array}$ & 0,10 & 3 & 0,30 & $\begin{array}{l}\text { Sekolah ini sudah bagus karena termasuk sekolah } \\
\text { Adiwiyata }\end{array}$ \\
\hline 4. Terletak di kabupaten & 0,15 & 4 & 0,60 & $\begin{array}{l}\text { Sekolah inicukup strategis karena terletak ditengah } \\
\text { kabupaten }\end{array}$ \\
\hline 5. Output kelulusan $100 \%$ & 0,10 & 4 & 0,40 & $\begin{array}{l}\text { Sekolah tersebut setiap tahunnya meluluskan alumninya } \\
\text { dengan prosentase } 100 \% \text { (keseluruhan lulus) }\end{array}$ \\
\hline $\begin{array}{l}\text { Kelemahan (W) } \\
\text { 1. Kurangnya siswa berbisnis dalam } \\
\text { kejuruannya masing- masing } \\
\end{array}$ & 0,15 & 3 & 0,45 & $\begin{array}{l}\text { Beberapa siswa yang terkadang kurang memahami dan } \\
\text { mendalami pelajaran yang disampaikan oleh guru. }\end{array}$ \\
\hline $\begin{array}{l}\text { 2. Banyak informasi lingkungan yang } \\
\text { tidak terkontrol }\end{array}$ & 0,15 & 3 & 0,45 & $\begin{array}{l}\text { Sekolah kurang terlibat dalam kegiatan-kegiatan } \\
\text { masyarakat dikarenakan kurangnya informasi dan } \\
\text { komunikasi }\end{array}$ \\
\hline $\begin{array}{l}\text { 3. Masih ada pemungutan biaya } \\
\text { sekolah dari orang tua siswa yang } \\
\text { belum efektif dan efesien }\end{array}$ & 0,10 & 2 & 0,20 & $\begin{array}{l}\text { Terkadang pihak sekolah masih mengadakan pungutan } \\
\text { dana kepada wali murid guna memenuhi kebutuhan } \\
\text { sekolah akan tetapi masih ada beberapa wali murid yang } \\
\text { belum dapat memenuhinya. }\end{array}$ \\
\hline $\begin{array}{ll}\text { 4. Kurangnya proses belajar } \\
\text { mengajarnya, lebih kejuruannya }\end{array}$ & 0,10 & 3 & 0,30 & $\begin{array}{l}\text { Proses pembelajaran lebih menitik beratkan pada praktek- } \\
\text { praktek kejuruan sedang unsur materi lebih sedikit }\end{array}$ \\
\hline $\begin{array}{l}\text { 5. Masih ada bangunan yang belum } \\
\text { efektif }\end{array}$ & 0,15 & 2 & 0,30 & Masih ada bangunaan yang harus diperbarui dan dibenahi \\
\hline JUMLAH S+W & 1,25 & & 3,85 & \\
\hline
\end{tabular}

Dilihat dari masing- masing butir kekuatan dan kelemahan pada matriks diatas dapat disimpulkan bahwa antara kekuatan dan kelemahan yang dimiliki SMKN 1 Pasir penyu seimbang dan sangat baik dari skor dan rating. Hal ini bisa dijadikan pelajaran untuk semua pihak sekolah bahwa kekuatan yang ada harus dipertahankan dan lebih-lebih bisa ditingkatkan lagi untuk lebih meksimal. guna meminimalisir kelemahan yang ada.

Tabel 2. Analisis Matriks EFAS (Eksternal Factor Analysis Strategy)

\begin{tabular}{|c|c|c|c|c|}
\hline $\begin{array}{l}\text { Faktor- faktor } \\
\text { Strategi Eksternal }\end{array}$ & Bobot & Rating & $\begin{array}{c}\text { Bobot } \\
* \\
\text { Rating }\end{array}$ & Komentar \\
\hline $\begin{array}{l}\text { Peluang }(\mathbf{O}) \\
\text { 1. Pemerintahan mempunyai perhatian lebih kepada } \\
\text { siswa SMKN } 1 \text { Pasir Penyu untuk dapat } \\
\text { mengembangkan keahliannya }\end{array}$ & 0,15 & 3 & 0,45 & $\begin{array}{l}\text { Sekolah dapat memajukan proposal } \\
\text { kepemerintah daerah untuk melengkapi sarana } \\
\text { prasarana sekolah }\end{array}$ \\
\hline $\begin{array}{l}\text { 2. Memepersiapkan program- program unggul atau } \\
\text { bakatnya untuk kedepannya }\end{array}$ & 0,10 & 3 & 0,30 & $\begin{array}{l}\text { Agar sekolah dapat mempersiapkan program } \\
\text { pembelajaran yang efektif }\end{array}$ \\
\hline $\begin{array}{l}\text { 3. Sekolah mampu bekerja sama dengan intansi lain } \\
\text { atau sekolah lain }\end{array}$ & 0,15 & 4 & 0,60 & $\begin{array}{l}\text { Agar dapat bersosialisasi dengan sekolah } \\
\text { lainnya }\end{array}$ \\
\hline $\begin{array}{l}\text { 4. Mempunyai kebijakan atau otoritas dalam } \\
\text { mengembangkan sekolah }\end{array}$ & 0,10 & 3 & 0,30 & $\begin{array}{l}\text { Agar suatu sekolah dapat berkembang setiap } \\
\text { tahunnya }\end{array}$ \\
\hline $\begin{array}{l}\text { 5. Sekolah bisa untuk lebih maju kedepannya dan } \\
\text { dipandang bagus oleh masyarakat }\end{array}$ & 0,10 & 3 & 0,30 & $\begin{array}{l}\text { Terbukti bahwa sekolah tersebut benar bagus } \\
\text { adanya menurut kalangan masyarakat }\end{array}$ \\
\hline $\begin{array}{l}\text { Ancaman (T) } \\
\text { 1. Tumbuhnya dan berkembangnya sekolah baru }\end{array}$ & 0,10 & 3 & 0,30 & Banyak nya sekolah lain yang juga faforit \\
\hline $\begin{array}{l}\text { 2. Masih ada mayarakat yang menceritakan atau } \\
\text { menjelekan sekolah tersebut }\end{array}$ & 0,10 & 2 & 0,20 & $\begin{array}{l}\text { Karana masyarakat luar belum tau apa saja } \\
\text { yang ada pada sekolah tersebut }\end{array}$ \\
\hline $\begin{array}{l}\text { 3. Kesulitan sekolah menempatkan siswanya ketika } \\
\text { sudah lulus sekolah }\end{array}$ & 0,05 & 2 & 0,10 & $\begin{array}{l}\text { Terkadang ada siswa yg badel atau apapaun } \\
\text { sehingga susah menepatkan siswanya }\end{array}$ \\
\hline
\end{tabular}




\begin{tabular}{|l|c|c|c|l|}
\hline \multicolumn{1}{|c|}{$\begin{array}{c}\text { Faktor- faktor } \\
\text { Strategi Eksternal }\end{array}$} & Bobot & Rating & $\begin{array}{c}\text { Bobot } \\
* \\
\text { Rating }\end{array}$ & \multicolumn{1}{c|}{ Komentar } \\
\hline 4. Lingkungan masyarakat & 0,10 & 3 & 0,30 & $\begin{array}{l}\text { Masih ada masyarakat yang menjelek atau } \\
\text { menceritakan sekolah tersebut }\end{array}$ \\
\hline $\begin{array}{l}\text { 5. } \begin{array}{l}\text { Kurangnya kemajuan teknologi atau bakat dalam } \\
\text { menjunjung pembelajaran }\end{array} \\
\text { JUMLAH O+T }\end{array}$ & 0,10 & 3 & 0,30 & $\begin{array}{l}\text { Belum maksimal guru dalam mengajarkan } \\
\text { materinya }\end{array}$ \\
\hline
\end{tabular}

Dapat dilihat dari peluangnya bisa mengembangkan program ataupun memebentuk siswa dapat mengembangkan ilmu yang mereka dapat disekolah tersebut. Dan ancaman nya adalah banyak masyarakat luar yang kadang masih tidak percaya bahwa sekolah itu bagus.

Tabel 3. Perhitungan Analisis SWOT SMKNegeri 1 Pasir Penyu

\begin{tabular}{|l|l|l|l|}
\hline IFAS & 3,85 & EFAS & 3,15 \\
\hline Total skor kekuatan $(\mathrm{S})$ & 2,15 & Total skor peluang $(\mathrm{O})$ & 1,95 \\
\hline Total skor kelemahan $(\mathrm{w})$ & 1,70 & Total skor Ancaman $(\mathrm{T})$ & 1,20 \\
\hline S-W $(2,15-1,70)$ & 0,45 & O-T $(1,95-1,20)$ & 0,75 \\
\hline
\end{tabular}

Berdasarkan tabel di atas maka nampak bahwa titik koordinat posisi SMK Negeri 1 Pasir Penyu pada titik-titik sumbu kekuatan 0, 45 dan sumbu peluang 0,75. Untuk lebih jelasnya dapat dilihat dalam diagram cartesius sebagaimana berikut:

$\begin{array}{ll}\text { Daerah ST } & \text { Strengths (S) } 2,15 \\ \text { Daerah SO } & \text { Threats (T) } 1,20 \\ \text { Daerah WO } & \text { Opportunity (O) } 1,95 \\ \text { Daerah WT } & \text { Weaknesses (W) } 1,70\end{array}$

Keterangan :

AFI $=3,85$, dengan $(\mathrm{S}=2,15)$ dan $(\mathrm{W}=1,70)$, jadi $(\mathrm{S}-\mathrm{W}=2,15-1,70=0,45)$

$\mathrm{AFE}=3,15$, dengan $(\mathrm{O}=1,95)$ dan $(\mathrm{T}=1,20)$, jadi $(\mathrm{O}-\mathrm{P}=1,95-1,20=0,75)$

Berikut Diagramnya:

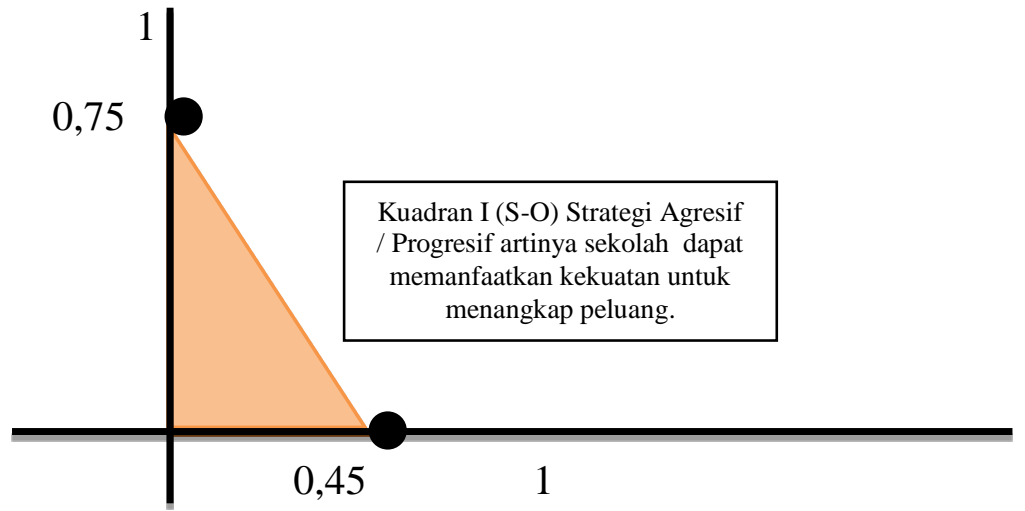

Gambar 1. Kuadran I (S-O) Strategi Agresif / Progresif

Berdasarkan analisis SWOT di atas dapat disimpulkan bahwa SMK N 1 Pasir Penyu berada pada Kuadran 1 berarti posisi ini menandakan sekolah tersebut kuat dan berpeluang, saran strategi yang diberikan adalah Agresif/ Progresif, artinya sekolah ini dalam kondisi baik sehingga memungkinkan untuk melakukan perluasan, memperbesar pertumbuhan dan meraih kemajuan secara maksimal. Perencanaan strategis yang disusun secara sistematis berdasarkan analisis SWOT dapat menghasilkan produk renstra serta dapat menjadi pedoman dalam penyusunan Rencana Kerja Sekolah (RKS) dan Rencana Kegiatan dan Anggaran Sekolah (RKAS) dengan tujuan agar mutu sekolah terus meningkat sehingga daya saing yang dimiliki sangat kuat.

Hal senada dengan Rangkuti (2009) yang menjelaskan: dengan analisis SWOT maka dapat diidentifikasi komponen Strengths yaitu beberapa faktor atau hal yang dinilai sebagai sebuah kelebihan dari suatu organisasi; Weaknesses yaitu komponen yang dinilai menghambat keberhasilan suatu organisasi; Opportunity yaitu kemungkinan yang dapat dicapai apabila sebuah organisasi berpotensi dan mampu berkembang secara optimal, dan Threats yaitu kemungkinan yang mungkin terjadi atau pengaruh terhadap kesinambungan sebuah organisasi. Posisi kuadran suatu organisasi akan terlihat dengan analisis SWOT, 
sehingga dapat diketahui pada posisi manakah organisasi yang bersangkutan. Hasil penelitian ini melalui analisis SWOT menunjukkan bahwa pada aspek input, proses maupun output SMK N 1 Pasir penyu berada pada kuadran S-O yang bermakna bahwa SMK N 1 Pasir Penyu kuat dan berpeluang untuk memenangkan persaingan. Rekomendasi atau saran strategi yang diberikan adalah agresif, artinya organisasi dalam kondisi prima untuk terus maksima melakukan perkembangan, memperbesar pertumbuhan demi meraih kemajuan sekolah.

Penggunaan analsisi SWOT untuk melihat suatu posisi sebuah organisasi dalam hal ini adalah sekolah, telah banyak dilakukan pula oleh peneliti-peneliti sebelumnya di antaranya adalah: 1) penelitian yang dilakukan Rozari (2011) di SMK St. Petrus Comoro Dili Timor Leste; 2) Suharti, (2013) di SDN 1 Ngadirejo Kecamatan Ngadirejo Kabupaten Temanggung; 3) Sumarni (2011) di SMP Kristen Satya Wacana Salatiga. Hasil penelitian ketiganya mengungkapkan bahwa untuk menggali kekuatan, kelemahan, peluang dan ancaman sebuah organisasi dibutuhkan media analisa yang akurat, analisis yang dimaksud yaitu analisis SWOT.

Sesuai dengan hasil penelitian ini, diharapkan SMK N 1 Pasir penyu dapat menjadikan hasil dari analisis SWOT sebagai pijakan untuk menyusun restra, RKS maupun RKAS untuk mencapai mutu sekolah yang diinginkan. Dengan analisis SWOT maka sekolah dapat mengevaluasi diri sehingga akan semakin memantapkan pijakan perencanaan seluruh kegiatan sekolah baik akademik maupun non akademik. Sekolah akan mengetahui di mana posisinya berada sehingga tahu seluruh komponen kelebihan, kekurangan, peluang, dan hambatan yang dimilikinya. Perencananan harus lebih matang bukan hanya sekedar formalitas pelengkap administrasi. Setiap sekolah mempunyai analisis SWOT yang berbeda-beda, sehingga istilah mpenyususnan RKS, RKAS dan renstra dengan meng copy sekolah lainpun harus dihindari.

\section{SIMPULAN}

Dengan analisis SWOT dan melalui tahap analisis matriks berskala bobot dan rating dapat disimpulkan bahwa; Analisis SWOT didasarkan pada logika yang dapat memaksimalkan kekuatan, dan Peluang, namun secara bersamaan dapat meminimalkan kelemahan dan ancaman. Proses pengambilan keputusan strategis berhubungan dengan pengembangan visi, misi, tujuan, serta beberapa kebijakan dan program kegiatan sekolah. Hasil dari pembahasan dan keseluruhan analisis SWOT baik dari sisi internal maupun eksternal, dapat disimpulkan bahwa SMK N 1 Pasir Penyu berada pada posisi Kuadran I. Makna dari posisi Kuadran I (Agresif) adalah SMK N 1 Pasir Penyu mempunyai kekuatan dan peluang untuk mendukung daya saing sekolah dan meningkatkan mutu sekolah.

Untuk meningkatkan daya saing sekolah dari segi faktor internal, dapat disusun beberapa rencana strategis di antaranya:

1. Peran seluruh warga sekolah untuk selalu menanamkan jiwa siswa dalam berbisnis sesuai bidangnya atau kejuruannya.

2. Aktif dalam mengikuti informasi positif terkini terkait lingkungan sekitar sekolah.

3. Membuat alternatif atau terobosan baru terkait masalah iuran yang dibebankan kepada wali siswa.

4. Menyeimbangkan porsi materi dengan porsi praktek di sekolah.

5. Tanggap dalam perbaikan bangunan sekolah.

Rencana strategis yang dibuat untuk meningkatkan daya saing sekolah dari segi faktor eksternal di antaranya:

1. Tetap semangat membuat program-program menarik yang lebih beda dari sekolah-sekolah sekitar.

2. Pengeimplementasian manajemen HUMAS yang efektif dalam menjalin relasi yang baik dengan masyarakat.

3. Menambah relasi dengan perusahaan atau unit kerja lainnya untuk menawarkan alumni-alumni yang telah mampu dan siap untuk dipromosikan.

4. Selalu mengikuti perkembangan dengan menggunakan teknologi mutakhir dalam proses pembelajaran dan praktek lapangan.

\section{REFERENSI}

Depdiknas. (2002). Ringkasan Kegiatan Belajar Mengajar. Jakarta: Depdiknas.

Marginson, S. and Wende, M. Van der. (2007). Education to Rank or to Be Rangked: The Impact of Global Ranking in Higher. Journal of Studies in International Education.

Pearce and Robinson. 2008, Manajemen Strategic: Formulasi, Implementasi, dan Pengendalian, Jakarta: Salemba Empat.

Rangkuti, F. (2009). Analisis SWOT TeknikMembedah Kasus Bisnis, Jakarta: PT. Gramedia Pustaka Utama.

Rahayu, A. (2008). Strategi Pemasaran Model Untuk Keunggulan. Bandung: Rizqi Press.

Rozari, A.M. (2011). Rencana Strategis Peningkatan Mutu Sekolah Dengan Analisis SWOT di SMK St. Petrus Comoro Dili Timor Leste. Tesis. Salatiga: Program Pasca Sarjana Magister Manajemen Pendidikan.

Sagala, S. (2010). Manajemen Strategik Dalam Peningkatan Mutu Pendidikan. Bandung: Alfabeta.

Suharti, R.(2013). Alternatif Strategi Peningkatan Mutu Sekolah Berdasarkan Analisis SWOT di SDN 1 Ngadirejo Kecamatan Ngadirejo Kabupaten Temanggung.Tesis.Salatiga: Program Pasca Sarjana Magister Manajemen Pendidikan. 
Sumarni, N. (2011). Strategi Peningkatan Mutu Sekolah Berdasarkan Analisa SWOT Pada SMP Kristen Satya Wacana Salatiga. Tesis, Salatiga: Program Pasca Sarjana Magister Manajemen Pendidikan. 